\title{
Sorption Characteristics for Multiple Adsorption of Heavy Metal Ions Using Activated Carbon from Nigerian Bamboo
}

\author{
Ademiluyi Falilat Taiwo, Nze Jane Chinyere \\ Department of Chemical/Petrochemical Engineering, Faculty of Engineering, Rivers State University of Science \\ and Technology, Port Harcourt, Nigeria \\ Email: ademuluyi@yahoo.com
}

Received 22 March 2016; accepted 25 April 2016; published 28 April 2016

Copyright (C) 2016 by authors and Scientific Research Publishing Inc.

This work is licensed under the Creative Commons Attribution International License (CC BY). http://creativecommons.org/licenses/by/4.0/

cC) (7) Open Access

\begin{abstract}
Sorption characteristics of multiple adsorption of six heavy metal ions often found in refinery waste waters using activated carbon from Nigerian bamboo was investigated. The bamboo was cut, washed and dried. It was carbonized between $350^{\circ} \mathrm{C}-500^{\circ} \mathrm{C}$, and activated at $800^{\circ} \mathrm{C}$ using nitric acid. Simultaneous batch adsorption of different heavy metal ions $\left(\mathrm{Cd}^{2+}, \mathrm{Ni}^{2+}, \mathrm{Pb}^{2+}, \mathrm{Cr}^{3+}, \mathrm{Cu}^{2+}\right.$ and $\mathrm{Zn}^{2+}$ ) in same aqueous solution using activated carbon from Nigerian bamboo was carried out. The adsorption process had a better fit for the Freundlich, Temkin isotherm and Dubinin-Radushkevich (DRK) isotherm models but could not fit well into Langmuir isotherm. Adsorption isotherms showed that there is competition among various metals for adsorption sites on Nigerian bamboo. The DRK model was used to determine the nature of the sorption process and was found to be physical and chemical, with sorption energy of metal ions ranging from $(7-10 \mathrm{~kJ} / \mathrm{mol})$. The adsorption of $\mathrm{Cd}^{2+}, \mathrm{Zn}^{2+}, \mathrm{Pb}^{2+}$ and $\mathrm{Ni}^{2+}$ ions was chemisorptions and that of $\mathrm{Cu}^{2+}$ and $\mathrm{Cr}^{3+}$ ions was cooperative adsorption. Therefore, this study revealed that Nigerian bamboo can serve as a good source of activated carbon with multiple and simultaneous metal ions-removing potentials and may serve as a better replacement for commercial activated carbons in applications that warrant their use.
\end{abstract}

\section{Keywords}

Multiple, Batch Adsorption, Heavy Metal Ions, Activated Carbon, Nigerian Bamboo

\section{Introduction}

Heavy or toxic metals are trace metals like mercury, nickel, lead, arsenic, cadmium, aluminum, platinum, and 
copper that are at least five times denser than water. As such, they are stable elements and cannot be metabolized by the body. They can be passed into the food chain to humans via waste waters from industrial and domestic activities. Heavy metals are taken into the body via inhalation, ingestion, and skin absorption. Heavy metals such as Chromium, Cadmium, lead, Copper, Zinc and Nickel are often found in refinery waste waters and are carcinogenic or toxic to the environment [1].

The removal of toxic heavy metals has been carried out by several researchers [2]-[6], using activated carbons made from peanut shells, raw and pretreated clinoptilolite, Chitosan, Agar and a commercial carbon (Merck 2514). The studies showed that selective metal ion adsorption of copper, lead, cadmium, zinc and nickel is possible in same aqueous solution. The competitive adsorption order and sequence of selection of heavy metals ions varies for different adsorbents. In the multi-element adsorption using kaolinite adsorption order of $\mathrm{Pb}<\mathrm{Cu}$ $<\mathrm{Zn}<\mathrm{Cd}$ was obtained [7]. The selectivity sequence was given as $\mathrm{Co}^{2+}>\mathrm{Cu}^{2+}>\mathrm{Zn}^{2+}>\mathrm{Mn}^{2+}$ during the removal of heavy metal cations by natural zeolites [8]. The sorption of $\mathrm{Pb}^{2+}, \mathrm{Cu}^{2+}, \mathrm{Fe}^{3+}$, and $\mathrm{Cr}^{3+}$ on natural clinoptilolite showed that equilibrium was favorable for $\mathrm{Pb}^{2+}$, unfavourable for $\mathrm{Cu}^{2+}$, and of sigmoid shape for $\mathrm{Cr}^{3+}$ and $\mathrm{Fe}^{3+}$ [9]. In the study of Competitive adsorption of heavy metals onto sesame straw biochar in aqueous solutions, adsorption sequence of $\mathrm{Pb}>\mathrm{Cu}>\mathrm{Cr}>\mathrm{Zn}>\mathrm{Cd}$ in the multimetal adsorption isotherm was obtained [10].

The use of activated carbon from Nigerian Bamboo from previous single metal adsorption studies was very effective in the removal of heavy metal ions in aqueous solution [11]. Another study also showed that Nigerian bamboo activated with Nitric acid can effectively and selectively adsorb multiple heavy metals ions (Chromium, Cadmium, lead, Copper, Zinc and Nickel, often found in refinery waste waters) in same aqueous solution [12]. But no model was developed to predict the amount of multi-heavy metal ions simultaneously adsorbed in same aqueous solution using Nigerian Bamboo and the sorption characteristics was not studied for multi-metal adsorption.

Therefore, the objective of this research is to investigate the sorption characteristics of multiple and simultaneous adsorption of six heavy metal ions often found in refinery waste waters using activated carbon from Nigerian bamboo.

\section{Materials and Methods}

\subsection{Materials}

The materials used for this study are as follows: Granular activated carbon produced from Nigerian waste Bamboo, distilled water, Nitric acid, metallic salts containing Nickel, Copper, Zinc, Cadmium, Lead and Chromium ions. All the salts used to prepare the solutions were of analytic grade. Other equipments and apparatus used for the research are: An analytical weighing balance (+0.001, Adams AFP 360L), pyrolyzer with pyrex condenser, Electric burner, Measuring cylinder, Heating mantle, Desiccators, Crucibles, Funnels and filter paper, Digital weighing Balance, Mortar and pestle, $\mathrm{pH}$ meter, Spatula, Burette and retort stand, Beakers, conical flasks, stirrer, Muffle furnace, sieves (150 $\mu \mathrm{m})$, Cutting machine and oven, Atomic Absorption Spectrophotometer (APHA 301A).

\subsection{Methods}

\subsubsection{Preparation of Bamboo Samples}

The Bamboo was cut into small sizes of about $2 \mathrm{~cm}$ long with a cutting machine. After the cutting, pieces of bamboo were washed thoroughly with distilled water to remove all the adherent extraneous matter. The bamboo was then dried in the oven.

\subsubsection{Carbonization Process}

$2 \mathrm{~kg}$ of Bamboo pieces were weighed into a reactor. The Bamboo was pyrolysed between $\left(350^{\circ} \mathrm{C}-500^{\circ} \mathrm{C}\right)$ in the absence of air for two hours, 30 minutes [13]. The distillate formed during the pyrolysis was collected by the receiver connected to a condenser. The charred material was cooled at room temperature before discharging it into a container.

\subsubsection{Chemical Activation}

The carbonated material was crushed. The crushed sample was screened using $1.18 \mathrm{~mm}$ sieve in order to get a 
uniform size of the particle. $100 \mathrm{~g}$ of carbonized bamboo was carefully weighed and put in beaker containing $150 \mathrm{~cm}^{3}$ of Nitric acid. The solution was stirred until the mixture formed a paste. The paste was heated in an oven in order to reduce the moisture content. The crucible was then transferred into a muffle furnace where it was heated for 1 hour at a temperature of $800^{\circ} \mathrm{C}$ in the absence of air so as to increase the surface area to volume ratio of the sample for proper adsorption. It was then cooled at room temperature and was washed with distilled water until the $\mathrm{pH}$ value was approximately 7 , showing no trace of nitric acid. After washing, the activated carbon was then dried. The carbon was sieved again using a sieve of $150 \mu \mathrm{m}$ based on previous works [14], and the final products are kept in an air tight containers. Nitric acid was found to be the best for metal ion adsorption and so was used as previously reported [11].

\subsubsection{Characterization of Activated Carbon Produced}

The characterization of the activated carbon involves the determination of properties such as bulk density, percentage burnt off, moisture content, ash content, particle size, benzene adsorption, methylene blue and iodine number [13].

\subsubsection{Determination of Adsorption Capacity}

Six metal ions $\left(\mathrm{Cd}^{2+}, \mathrm{Ni}^{2+}, \mathrm{Pb}^{2+}, \mathrm{Cr}^{3+}, \mathrm{Cu}^{2+}\right.$ and $\left.\mathrm{Zn}^{2+}\right)$ often found in industrial waste waters especially refineries were used for this study. Different concentrations of these heavy metals ions in solution were prepared. Batch adsorption of the six metal ions onto bamboo activated carbon was carried out in the same aqueous solution for the different concentrations of these heavy metals ions in solution i.e. using adsorbate/adsorbent ratio of 100:1. Each sample was stirred, and adsorption was carried out for 30, 45, 90, 120, 240 and 990 minutes till equilibration. After each time interval the sample was filtered out with filter paper to remove any carbon particles in the filtrate. This process was repeated for different concentrations of these heavy metals ions in same solution. $5 \mathrm{ml}$ of the resulting filtrate from each sample was diluted with $50 \mathrm{ml}$ of $2 \%$ nitric acid and metals ions in filtrate after digestion were analyzed using Atomic Absorption Spectrophotometer (APHA 301A).

\subsection{Metal Uptake}

The amount of metal adsorbed per unit weight of adsorbent, $Q_{e}(\mathrm{mg} / \mathrm{g})$, was calculated from Equation 1 [15].

$$
Q_{e}=\frac{\left(C_{o}-C_{e}\right) V}{M}
$$

where;

$$
\begin{aligned}
& C_{o}=\text { The initial metal concentration in liquid phase }\left(\mathrm{mg} \cdot \mathrm{L}^{-1}\right) \\
& C_{e}=\text { The liquid phase metal concentration at equilibrium }\left(\mathrm{mg} \cdot \mathrm{L}^{-1}\right) \\
& V=\text { The volume of metal solution used }(\mathrm{L}) \\
& M=\text { The mass of adsorbent used }(\mathrm{g})
\end{aligned}
$$

\subsection{Adsorption Isotherms}

Isotherm Models: The most common sorption models were used to fit the experimental data which has been applied for single and multi-metal [8] [16]-[18]. These are Freundlich, Langmuir, Temkin isotherms and DRK isotherms.

a) The first model is the Freundlich model. It often represents an initial surface adsorption followed by a condensation effect resulting from extremely strong solute-solute interaction. Freundlich model is of the form.

$$
Q_{e}=K_{f}\left(C_{e}\right)^{1 / n}
$$

where:

$K_{f}=$ The Freundlich constant related to the adsorption capacity.

$n=$ The Freundlich constant related to the adsorption intensity.

$C_{e}=$ The liquid phase metal concentration at equilibrium $\left(\mathrm{mg} \cdot \mathrm{L}^{-1}\right)$

The values of $K_{f}$ and $n$ was obtained by plotting $Q_{e}$ versus $C_{e}$ and fitting the data to power law equation (i.e. $y$

$=k X^{n}$ ) using Microsoft excel applications 2007. 
b) The Langmuir model assumes that equilibrium is attained when a monolayer of the adsorbate molecules saturates the adsorbent. The linear form of Langmuir model is:

$$
\frac{C_{e}}{Q_{e}}=\frac{1}{Q_{m} b}+\frac{C_{e}}{Q_{m}}
$$

$C_{e}=$ The equilibrium concentration of the adsorbate $(\mathrm{mg} / \mathrm{L})$

$Q_{e}=$ The amount of adsorbate adsorbed per unit mass of adsorbent $(\mathrm{mg} / \mathrm{L})$

$b=$ A constant related to the affinity between the adsorbent and the adsorbate.

$Q_{m}=$ The theoretical monolayer saturation capacity

The values of $Q_{m}$ and $b$ was determined by plotting $C_{e} / Q_{e}$ against $C_{e}$. so that the Slope $=1 / Q_{m}$ and intercept $=1 / Q_{m} b$.

c) The third model is the Temkin. The Temkin isotherm is also often used to represent the equilibrium adsorptive behavior between two phases in an adsorption system. The Temkin isotherm is expressed as:

$$
Q_{e}=B \ln A+B \ln C_{e}
$$

where: $A$ is the Temkin isotherm constant (L/g), $B=R T / b, b$ is the Temkin constant related to heat of sorption $(\mathrm{J} / \mathrm{mol}), R$ is the gas constant $(8.314 \mathrm{~J} / \mathrm{mol} \mathrm{K})$, and $T$ is the absolute temperature $(\mathrm{K})$.

d) The fourth model used is the Dubinin-Radushkevich (DRK) model which has the linear form:

$$
\ln Q_{e}=\ln Q_{m}-\beta \varepsilon^{2}
$$

where $Q_{m}$ is the maximum sorption capacity, $\beta$ is the activity coefficient related to mean sorption energy, and $\varepsilon$ is the Polanyi potential, which is equal to

$$
\varepsilon=R T \ln \left(1+1 / C_{e}\right)
$$

where $R$ is the gas constant $(\mathrm{kJ} / \mathrm{kmolK})$.

The slope of the plot of $\ln Q_{e}$ versus $\varepsilon^{2}$ gives $\beta\left(\mathrm{mol}^{2} / \mathrm{J}^{2}\right)$ as slope and the intercept yields the sorption capacity, $Q_{\mathrm{m}}(\mathrm{mg} / \mathrm{g})$. The values of the adsorption energy, $E$, was obtained from the relationship in Equation 7.

$$
E=\frac{1}{\sqrt{(-2 \beta)}}
$$

Table 1 shows the characterization of activated carbon of the Nigerian Bamboo used for the batch adsorption of Nickel, Copper, Zinc, Lead, Cadmium, and Chromium ions in solution.

\section{Results and Discussion}

\subsection{Adsorption Modeling}

\subsubsection{Freundlich Isotherm Model for Multiple Adsorption of Different Metal Ions in Aqueous Solution}

Figure 1 shows Freundlich isotherm for the multiple and simultaneous batch adsorption of different metal ions onto activated carbon from Nigerian Bamboo. The equilibrium data for the adsorption of these heavy metal ions were fitted to the Freundlich isotherm. A linear plot was obtained when $Q_{e}$ was plotted against $C_{e}$ over the entire concentration range in Figure 1. The amount of metal ions adsorbed $Q_{e}$ increased with equilibrium concentrations $C_{e}$ for all the heavy metal adsorbed. The amount of lead selectively adsorbed was more than other metals. Similar report was obtained, in which Lead ions were adsorbed more than any other metal [19]. The effectiveness of Nigerian Bamboo carbon to selectively and competitively adsorbed all the heavy metals at the same time in the same aqueous solution is also seen from Figure 1.

The Freundlich isotherm model parameters (obtained from the slope, the intercept and the coefficient of determination from Figure 1) and the statistical fits of the sorption data to this equation are shown in Table 2. It was observed from Table 2 that the adsorption conforms to the Freundlich model since the value of the coefficient of determination $\left(\mathrm{R}^{2}\right)$ is greater than 0.9 , indicating that the isotherms are consistent with Freundlich model. The adsorption intensity (n) was obtained from the slopes as well as the adsorption capacity $\left(K_{f}\right)$ from intercepts 


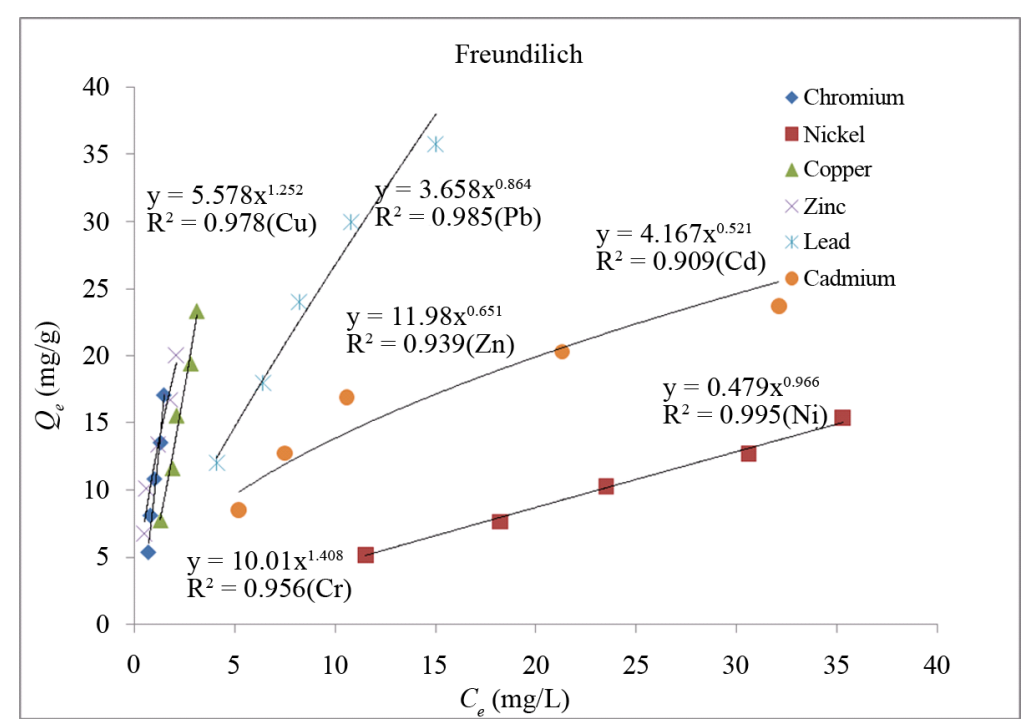

Figure 1. Freundlich Isotherms for the multiple Batch Adsorption of different Heavy metals ions onto Activated Carbon from Nigerian Bamboo in same aqueous solution.

Table 1. Characterization of activated carbon from Nigerian bamboo.

\begin{tabular}{cccc}
\hline S/No. & Parameters & Units & Locally made Bamboo activated carbon \\
\hline 1 & Bulk Density & $\mathrm{g} / \mathrm{cm}^{3}$ & 0.458 \\
2 & Iodine number & $\mathrm{g}$ of Iodine $/ \mathrm{kg}$ of carbon & 1160 \\
3 & Ash content & $\%$ & 3.900 \\
4 & Methylene-Blue adsorptive capacity & $\mathrm{mg} / \mathrm{g}$ & 941.325 \\
5 & Moisture Content & $\%$ & 5.09 \\
6 & Benzene adsorptive capacity & $\mathrm{mg} / \mathrm{g}$ & 148.9 \\
7 & Particle size & $\mu \mathrm{m}$ & $>150$ \\
8 & Burnt off & 67.5 & $\%$ \\
\hline
\end{tabular}

Table 2. Freundlich, Temkin constants related to multiple adsorption of different metal ions from aqueous solution using activated carbon from Nigerian bamboo.

\begin{tabular}{ccccccccc}
\hline \multirow{2}{*}{$\begin{array}{c}\text { Heavy metal } \\
\text { ions adsorbed }\end{array}$} & \multicolumn{3}{c}{ Freundlich Isotherm } & \multicolumn{5}{c}{ Temkin Isotherm } \\
\cline { 2 - 8 } & $k_{f}$ & $n$ & $\mathrm{R}^{2}$ & $A$ & $B$ & $b=R T / B$ & $\mathrm{R}^{2}$ \\
\hline Nickel & 0.479 & 1.035 & 0.995 & 0.143 & 8.89 & 281.498 & 0.958 \\
Copper & 5.578 & 0.799 & 0.978 & 1.134 & 17.52 & 142.838 & 0.955 \\
Zinc & 11.98 & 1.536 & 0.939 & 5.004 & 7.999 & 312.853 & 0.952 \\
Lead & 3.658 & 1.157 & 0.985 & 0.439 & 18.88 & 132.548 & 0.99 \\
Cadmium & 4.167 & 1.919 & 0.909 & 0.638 & 7.969 & 314.031 & 0.97 \\
Chromium & 10.01 & 0.710 & 0.956 & 2.116 & 14.42 & 173.545 & 0.974 \\
\hline
\end{tabular}

in Figure 1. Also the values of $1 / n$ obtained ranged from 0.521 to 1.408 from Figure 1 . The closer the value of $1 / n$ to zero the more heterogeneous the adsorption surface.

The Freundlich isotherm fits well with the experimental data. All the metal ions adsorbed had coefficient of determination $R^{2}>0.9$. This indicates that the Freundlich isotherm was very suitable for describing the multiple 
sorption of heavy metals ions using activated carbon from Nigerian Bamboo. Similar results were reported [20] during the Sorption of $\mathrm{Pb}(\mathrm{II}), \mathrm{Ni}(\mathrm{II}), \mathrm{Cu}(\mathrm{II})$ and $\mathrm{Cd}(\mathrm{II})$ from aqueous solution by olive stone waste, in which Freundlich model was found to provide the best correlation. A value of $1 / n$ below unity implies chemisorptions process, for $1 / n$ above one is an indicative of cooperative adsorption [17]. These implies that the adsorption of $\mathrm{Cd}^{2+}, \mathrm{Zn}^{2+}, \mathrm{Pb}^{2+}$ and $\mathrm{Ni}^{2+}$ ions was chemisorptions and that of $\mathrm{Cu}^{2+}$ and $\mathrm{Cr}^{3+}$ was cooperative adsorption. As can be seen in Table 2, the constants $n$ of the heavy metal ions adsorbed from the Freundlich model change (1.919 0.710 ) in the order of $\mathrm{Cd}^{2+}>\mathrm{Zn}^{2+}>\mathrm{Pb}^{2+}>\mathrm{Ni}^{2+}>\mathrm{Cu}^{2+}>\mathrm{Cr}^{3+}$. The value of $\mathrm{n}$ gives an indication of how favorable the adsorption processes. The multiple adsorption of cadmium, zinc and lead ions by Nigerian bamboo carbon is more favorable than for Nickel, copper and chromium ions using Freundlich model.

\subsubsection{Temkin Isotherm for the Multiple Adsorption of Different Metals onto Activated Carbon from Bamboo}

A linear relationship was also exhibited from the plot of amount of metal ions adsorbed $\left(Q_{e}\right)$ at equilibrium against the natural logarithm of equilibrium concentrations in Figure 2 for Nickel, Copper, Zinc, Lead, Cadmium, and Chromium using the Temkin Model. Temkin model parameters and the statistical fits of the sorption data to Temkin model are as shown in Table 2 and indicated that the adsorption conforms to the Temkin model since the value of the coefficient of determination $\left(\mathrm{R}^{2}\right)$ is greater than 0.9 for all the metal ions adsorbed. Hence Temkin model can also be used to predict the multiple adsorption of these metal ions using bamboo activated carbon. The values of Temkin constant (b) from Table 2, related to heat of sorption differ for each heavy metal ion in same solution. Temkin isotherm takes into accounts of indirect adsorbent-adsorbate interactions on adsorption isotherms.

The Temkin isotherm model assumes that the adsorption heat of all molecules decreases linearly with the increase in coverage of the adsorbent surface, and that adsorption is characterized by a uniform distribution of binding energies, up to a maximum binding energy [21]. The Temkin adsorption isotherm model helps to evaluate the adsorption potentials of the adsorbent for adsorbates [22]. From Table 2, the value of b related to the heat of adsorption using Temkin model reduce according to the sequence $\mathrm{Pb}^{2+}<\mathrm{Cu}^{2+}<\mathrm{Cr}^{3+}<\mathrm{Ni}^{2+}<\mathrm{Zn}^{2+}<$ $\mathrm{Cd}^{2+}$, while the value of constant $\mathrm{B}$ increase in the order $\mathrm{Pb}^{2+}>\mathrm{Cu}^{2+}>\mathrm{Cr}^{3+}>\mathrm{Zn}^{2+}>\mathrm{Ni}^{2+}>\mathrm{Cd}^{2+}$.

The value of $b$ for $\mathrm{Pb}^{2+}$ ions adsorbed was the least $(132 \mathrm{~J} / \mathrm{mol})$ and Cadmium was the largest $(314 \mathrm{~J} / \mathrm{mol})$. These values revealed that it was very easy to adsorb lead, copper and chromium ions during the multiple adsorption than other metal ions using activated carbon from Nigerian bamboo. Similar results was reported during the adsorption of $\mathrm{Pb}, \mathrm{Zn}$ and $\mathrm{Cu}$ by Kaolinite [22].

\subsubsection{Langmuir Isotherm for the Multiple Adsorption of Different Metals onto Activated Carbon from Bamboo}

Figure 3 shows Langmuir Isotherm for the batch multiple and simultaneous adsorption of different heavy metal

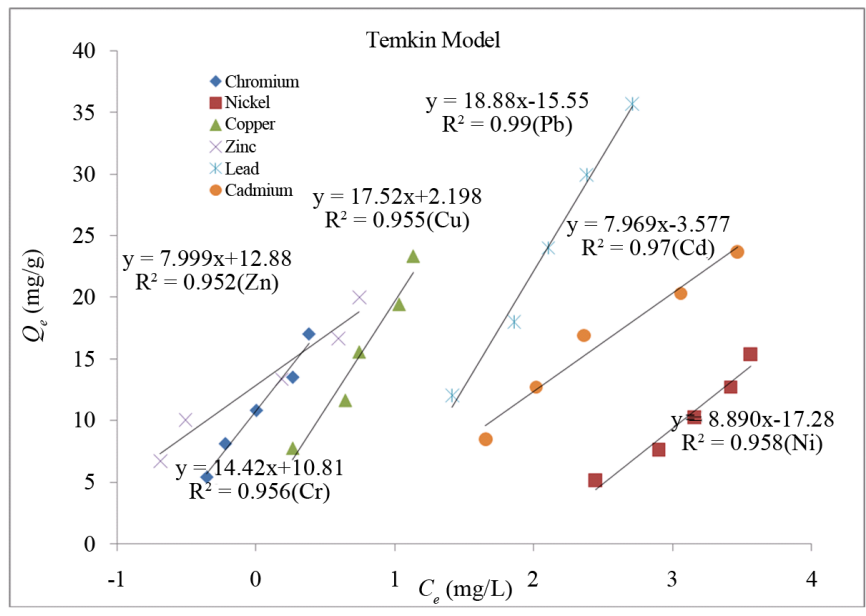

Figure 2. Temkin isotherms for the multiple Batch adsorption of different Heavy metals Ions onto activated Carbon from Nigerian bamboo in Same aqueous solution. 


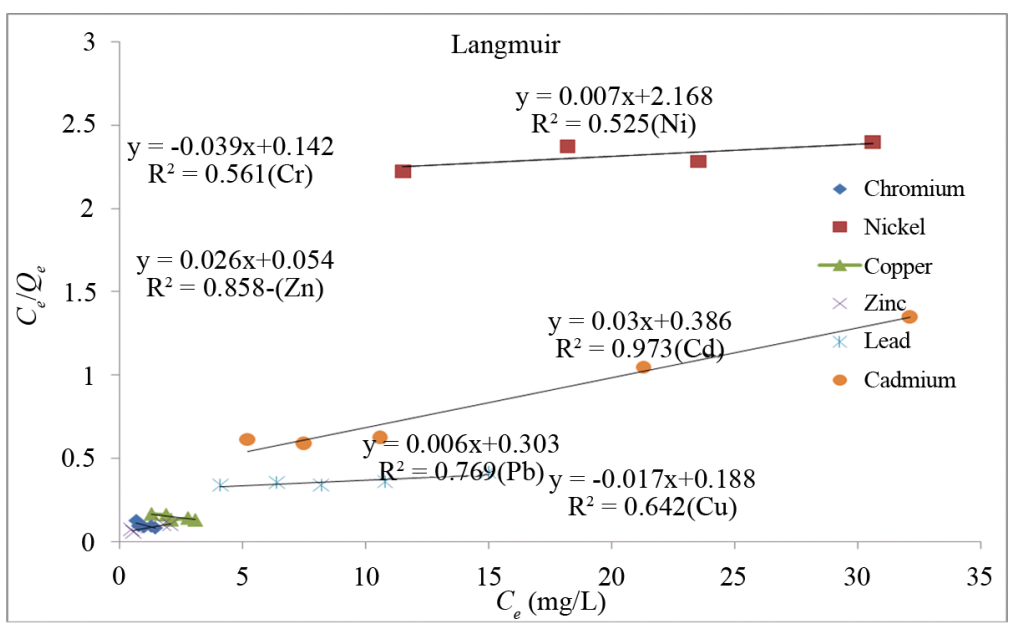

Figure 3. Langmuir Isotherm for the Batch adsorption of different Heavy Metal Ions onto activated Carbon of Nigerian Bamboo.

ions using activated carbon from Nigerian Bamboo. The equilibrium data for the adsorption of these heavy metal ions were fitted to the Langmuir Isotherm. A linear plot was obtained when $C_{e} / Q_{e}$ was plotted against $C_{e}$ over the entire concentration range. The amount of adsorbate adsorbed increased with increase in equilibrium concentration for all the metals. The slope (b) which is known to be the adsorption intensity, the intercept $\left(Q_{m}\right)$ which is a measure of adsorption capacity and the coefficient of determination were determined from Figure 3. The Langmuir model parameters and the statistical fits of the sorption data to this equation are shown in Table 3. The data represented on Table 3 indicates that the multiple adsorption of the heavy metal ions did not fit well to the Langmuir isotherm model, since $\mathrm{R}^{2}$ is less than 0.9 for most of the metals. Adsorption of heavy metal ions are more favourable for single adsorption using Langmuir than in multiple and competitive adsorptions for Nigerian bamboo as adsorbent [14] [18].

Similarly, experimental data during adsorption of some heavy metals [3] were also applied to the Langmuir adsorption isotherm, but linear form of the Langmuir adsorption isotherm was not obtained. This was also observed in a similar study carried out [23] during the study of adsorption of $\mathrm{Pb}(\mathrm{II}), \mathrm{Cd}(\mathrm{II}), \mathrm{Ni}(\mathrm{II})$ and $\mathrm{Cu}(\mathrm{II})$ onto natural kaolinite clay. The results obtained from adsorption isotherm of kaolinite clay showed that the equilibrium data were better fitted with the Freundlich equation than with the Langmuir equation.

The Langmuir adsorption model deviates significantly in many cases (especially for multi-metal adsorption), primarily because it fails to account for the surface roughness of the adsorbent. Rough inhomogeneous surfaces have multiple site-types available for adsorption, and some parameters vary from site to site, such as the heat of adsorption. This mean that the surface of Nigerian Bamboo carbon is heterogonous with multilayer coverage.

\subsubsection{Dubinin-Radushkevich Isotherm for the Multiple Adsorption of Different Metals onto Activated Carbon from Bamboo}

Figure 4 shows Dubinin-Radushkevich (DRK) Isotherm for the multiple and simultaneous batch adsorption of different heavy metal ions using activated carbon from Nigerian Bamboo. The experimental data was fitted into DRK model to enable us determine the type of sorption process that exist when these six metal ions are simultaneously adsorbed by activated carbon from Nigerian Bamboo in same aqueous solution. The equilibrium data for the adsorption of these heavy metal ions were fitted to the DRK Isotherm. A linear plot was obtained when In $Q_{e}(\mathrm{~mol} / \mathrm{g})$ was plotted against $\varepsilon^{2}$ over the entire concentration range. The amount of adsorbate $Q_{e}$ adsorbed varies linearly with $\varepsilon^{2}$ for all the metal ions. Adsorption isotherms showed that there is competition among various metals for adsorption sites on Nigerian bamboo.

It was observed from Table 3 that the adsorption conforms to the DRK model, since the value of the coefficient of determination $\left(\mathrm{R}^{2}\right)$ is greater than 0.9 , indicating that the isotherms fitted well to DRK isotherm. The values of $\beta$ and $Q_{m}$, are listed in Table 3 with their corresponding value of the coefficient of determination, $\mathrm{R}^{2}$. It can be observed that the values of $\beta\left(\mathrm{mol}^{2} / \mathrm{J}^{2}\right)$ for $\mathrm{Ni}, \mathrm{Cu}$ and $\mathrm{Cr}$ ions are the same. $(1.00 \mathrm{E}-08)$ while that of $\mathrm{Zn}$ and $\mathrm{Cd}$ ions (5.00E-08) are also the same but lead was different $(7.00 \mathrm{E}-08)$. The same trend was observed for 


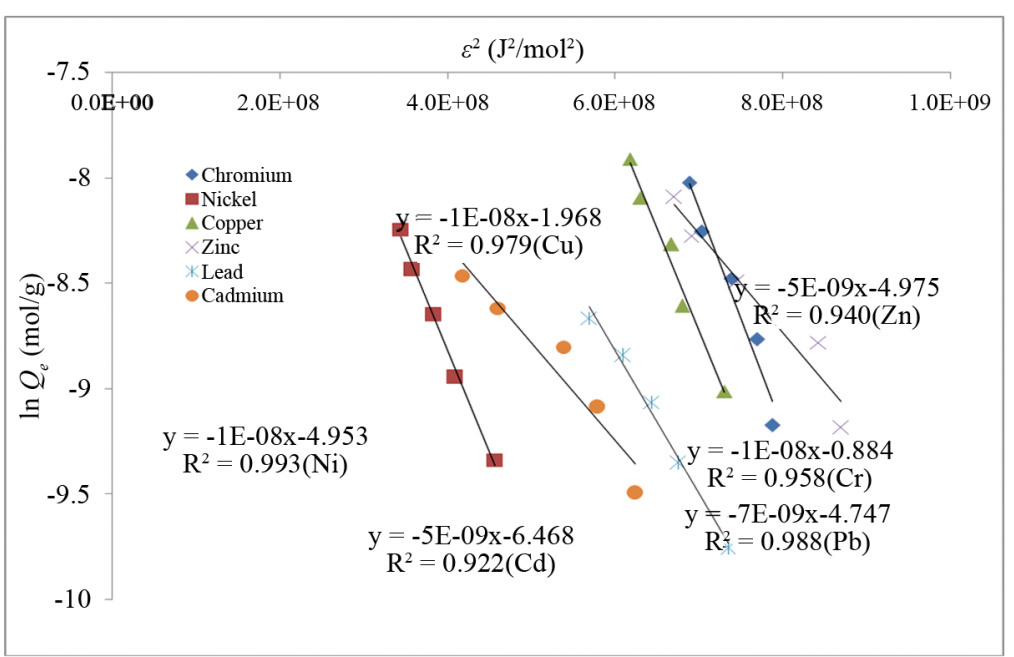

Figure 4. DRK Isotherm for the Batch Multiple Adsorption of Different Heavy Metal Ions onto Activated Carbon of Nigerian Bamboo.

Table 3. Langmuir isotherm and Dubinin-Radushkevich isotherm constants related to multiple adsorption of different metal ions from aqueous solution using activated carbon from Nigerian Bamboo.

\begin{tabular}{ccccccccc}
\hline \multirow{2}{*}{$\begin{array}{c}\text { Heavy metal ions } \\
\text { adsorbed }\end{array}$} & \multicolumn{3}{c}{ Langmuir Isotherm } & \multicolumn{5}{c}{ Dubinin-Radushkevich Isotherm } \\
\cline { 2 - 8 } & $Q_{\max } \mathrm{mg} / \mathrm{g}$ & $b$ & $\mathrm{R}^{2}$ & $Q_{m}(\mathrm{~mol} / \mathrm{g})$ & $\beta\left(\mathrm{mol}^{2} / \mathrm{J}^{2}\right)$ & $E(\mathrm{~kJ} / \mathrm{mol})$ & $\mathrm{R}^{2}$ \\
\hline Nickel & 142.857 & 65.8935 & 0.525 & 0.0071 & $1.00 \mathrm{E}-08$ & 7.071068 & 0.993 \\
Copper & -58.824 & -312.8911 & 0.642 & 0.1397 & $1.00 \mathrm{E}-08$ & 7.071068 & 0.979 \\
Zinc & 38.462 & 712.2507 & 0.858 & 0.0069 & $5.00 \mathrm{E}-09$ & 10 & 0.94 \\
Lead & 166.667 & 550.0550 & 0.769 & 0.0087 & $7.00 \mathrm{E}-09$ & 8.451543 & 0.988 \\
Cadmium & 33.333 & 86.3558 & 0.973 & 0.0016 & $5.00 \mathrm{E}-09$ & 10 & 0.922 \\
Chromium & -25.641 & -180.5706 & 0.561 & 0.4131 & $1.00 \mathrm{E}-08$ & 7.071068 & 0.958 \\
\hline
\end{tabular}

the values of the mean sorption energy for the metal ions $E(\mathrm{~kJ} / \mathrm{mol})$. The values of $E$ ranged between 7 - 10 $\mathrm{kJ} / \mathrm{mol}$ for the heavy metal ions adsorbed by Nigeria bamboo carbon, which shows that the sorption process is physical and chemical. It had been reported that the $E$ value ranges from 1 to $8 \mathrm{~kJ} / \mathrm{mol}$ for physical sorption and from 8 to $16 \mathrm{~kJ} / \mathrm{mol}$ for chemical sorption [24].

\section{Conclusion}

The sorption characteristics of multiple and simultaneous adsorption of six heavy metal ions often found in refinery waste waters using activated carbon from Nigerian bamboo was studied. The experimental data were more consistent for Freundlich, Temkin and DRK isotherm models and best fit the sorption process than Langmuir. Adsorption isotherms showed that there is competition among various metals for adsorption sites on Nigerian bamboo. The nature of the sorption process occurring during the adsorption process was found using the DRK isotherm model to be physical and chemical, with sorption energy ranging from (7 - $10 \mathrm{~kJ} / \mathrm{mol})$. The high multiple adsorption intensity ( $n>1$ for most of the metal ions adsorbed) of activated carbon from Nigerian Bamboo and its affinity for metal ions of Lead, Cadmium, Nickel, Copper, Zinc, and Chromium can help resolve many adsorption challenges in the industry and in water purification processes.

\section{References}

[1] Kocasoy, G. and Sahin, V. (2007) Heavy Metal Removal from Industrial Wastewater by Clinoptilolite. Journal Environmental Science and Health Part A, 42, 2139-2146. http://www.ncbi.nlm.nih.gov/pubmed/18074286 
http://dx.doi.org/10.1080/10934520701629617

[2] Myroslav, S., Boguslaw, B., Artur, P.T. and Jacek, N. (2006) Study of the Selection Mechanism of Heavy Metals (Pb ${ }^{2+}$, $\mathrm{Cu}^{2+}, \mathrm{Ni}^{2+}$, and $\mathrm{Cd}^{2+}$ ) Adsorption on Clinoptilolite Journal of Colloid and Interface Science, 304, 21-28. http://dx.doi.org/10.1016/j.jcis.2006.07.068

[3] Kermit, W, Hong, Y., Chung, W.S. and Wayne, E.M. (2006) Select Metal Adsorption by Activated Carbon Made from Peanut Shells. BioResources Technology, 97, 2266-2270. http://dx.doi.org/10.1016/j.biortech.2005.10.043

[4] Uzun, I. and Guzel, F. (2000) Adsorption of Some Metal Ions from Aqueous Solution by Activated Carbon and Comparison of Percentage Adsorption Results of Activated Carbon with Those of Some Other Adsorbents. Turkey Journal of chemistry, 24, 291-297. http://journals.tubitak.gov.tr/chem/issues/kim-00-24-3/kim-24-3-11-9907-9.pdf

[5] El-Eswed, B., Alshaaer, M., Yousef, R.I., Hamadneh, I. and Khalili, F. (2012) Adsorption of Cu(II), Ni(II), Zn(II), $\mathrm{Cd}(\mathrm{II})$ and $\mathrm{Pb}(\mathrm{II})$ onto Kaolin/Zeolite Based-Geopolymers. Advances in Materials Physics and Chemistry, 2, 119-125. http://dx.doi.org/10.4236/ampc.2012.24B032

[6] Bao, W.W., Zou, H.F., Gan, S.C., Xu, X.C., Ji, G.J. and Zheng, K.Y. (2013) Kinetic and Equilibrium Studies on the Adsorption of Heavy Metal ions from Aqueous Solution by Zeolite Based Oil Shale Ash. Journal of Chemical Research, 29, 126-131.

[7] Srivastava, P., Singh, B. and Angove, M. (2005) Competitive Adsorption Behavior of Heavy Metals on Kaolinite Journal of Colloid and Interface Science, 290, 28-38. http://www.ncbi.nlm.nih.gov/pubmed/15935360 http://dx.doi.org/10.1016/j.jcis.2005.04.036

[8] Erdem, E., Karapinar, N. and Donat, R. (2004) The Removal of Heavy Metal Cations by Natural Zeolites. Journal of Colloid and Interface Science, 280, 309-314. http://www.ncbi.nlm.nih.gov/pubmed/15533402 http://dx.doi.org/10.1016/j.jcis.2004.08.028

[9] Mier, M.V., Callejas, R.L., Gehr, R., Cisneros, B.E.J. and Alvarez, P.J.J. (2001) Heavy Metal Removal with Mexican Clinoptilolite: Multi-Component Ionic Exchange. Water Research, 35, 373-378. http://www.ncbi.nlm.nih.gov/pubmed/11228988 http://dx.doi.org/10.1016/S0043-1354(00)00270-0

[10] Park, J.-H., Ok, Y.S., Kim, S.-H., Cho, J.-S., Heo, J.-S., Delaune, R.D. and Seo, D.-C. (2016) Competitive Adsorption of Heavy Metals onto Sesame Straw Biochar in Aqueous Solutions Chemosphere, 142, 77-83. http://www.ncbi.nlm.nih.gov/pubmed/26082184 http://dx.doi.org/10.1016/j.chemosphere.2015.05.093

[11] Ademiluyi, F.T. and David-West, E.O. (2012) Effect of Chemical Activation on the Adsorption of Heavy Metals Using Activated Carbons from Waste Materials. ISRN Chemical Engineering, No. 1, Article ID: 67420. http://www.hindawi.com/isrn/Chemeng/2012/674209/

[12] Ademiluyi, F.T. and Nze, J.C. (2016) Multiple Adsorption of Heavy Metal Ions in Aqueous Solution Using Activated Carbon from Nigerian Bamboo. International Journal of Research in Engineering and Technology, 5, 164-169 http://esatjournals.net/ijret/2016v05/i01/IJRET20160501033.pdf

[13] Ademiluyi, F.T., Amadi, S.A. and Jacob, A.N. (2009) Adsorption and Treatment of Organic Contaminants Using Activated Carbon from Waste Nigerian Bamboo. Journal of Applied Sciences \& Environmental management, 13, 39-47. http://www.bioline.org.br/pdf?ja09036

[14] Ademiluyi, F.T. and Rodney, N. (2016) Effect of Process Parameters on the Single Adsorption of Zinc and Nickel Ions Using Activated Carbon from Waste Nigerian Bamboo. International Journal of Engineering and Applied Sciences, 3, 100-103. https://www.ijeas.org/download_data/IJEAS0301038.pdf

[15] Kannan, N. and Veemaraj, T. (2009) Removal of Lead (II) Ions by Adsorption Onto Bamboo Dust and Commercial Activated Carbons. E-Journal of Chemistry, 6, 247-256. http://dx.doi.org/10.1155/2009/515178

[16] Zacaria, R., Claire, G., Yves, A. and Pierrele, C. (2002) Adsorption of Several Metal Ions onto a Low-Cost Biosorbent. Journal of Environmental Science, 36, 2067-2073. http://dx.doi.org/10.1021/es0102989

[17] Foo, K.Y. and Hameed, B.H. (2010) Insights into the Modeling of Adsorption Isotherm Systems Chemical Engineering Journal, 156, 2-10. http://dx.doi.org/10.1016/j.cej.2009.09.013

[18] Ademiluyi, F.T. and Ujile, A.A. (2013) Kinetics of Batch Adsorption of Iron II Ions from Aqueous Solution Using Activated Carbon from Nigerian Bamboo. International Journal of Engineering and Technology, 3, 623-631. http://iet-journals.org/archive/2013/june_vol_3_no_6/481869136661933.pdf

[19] Covelo, E.F., Vega, F.A. and Andrade, M.L. (2007) Simultaneous Sorption and Desorption of Cd, Cr, Cu, Ni, Pb, and Zn in Acid Soils: I. Selectivity Sequences. Journal of Hazardous Materials, 147, 852-861. http://dx.doi.org/10.1016/j.jhazmat.2007.01.123

[20] Fiol, N., Villaescusa, I., Martínez, M., Miralles, N., Poch, J. and Serarols, J. (2006) Sorption of Pb(II), Ni(II), Cu(II) and Cd(II) from Aqueous Solution by Olive Stone Waste. Separation and Purification Technology, 50, $132-140$. 
http://dx.doi.org/10.1016/j.seppur.2005.11.016

[21] Piccin, J.S., Dotto, G.L. and Pinto, L.A.A. (2011) Adsorption Isotherms and Thermochemical Data of FD \& C Red $n^{\circ}$ 40 Binding by Chitosan. Brazilian Journal of Chemical. Engineering, 28, 295-304. http://dx.doi.org/10.1590/S0104-66322011000200014

[22] Shahmohammadi-Kalalagh, Sh., Babazadeh, H., Nazemi, A.H. and Manshouri, M. (2011) Isotherm and Kinetic Studies on Adsorption of $\mathrm{Pb}, \mathrm{Zn}$ and Cu by Kaolinite. Caspian Journal of Environmental Science, 9, 243-255. http://cjes.guilan.ac.ir/article_1073_900204a45496e0f87fc5733e7709027d.pdf

[23] Jiang, M.-Q., Jin, X.-Y., Lu, X.-Q. and Chen, Z.-L. (2010) Adsorption of Pb(II), Cd(II), Ni(II) and Cu(II) onto Natural Kaolinite Clay. Desalination, 252, 33-39. http://dx.doi.org/10.1016/j.desal.2009.11.005

[24] Zheng, H., Liu, D.H., Zheng, Y., Liang, S.P. and Liu, Z. (2009) Sorption Isotherm and Kinetic Modeling of Aniline on Cr-Bentonite. Journal of Hazardous Materials, 167, 141-147. http://dx.doi.org/10.1016/j.jhazmat.2008.12.093 